\title{
Distribuição de Salários de Professores e Outras Ocupações: Uma Análise para Graduados em Carreiras Tipicamente Ligadas à Docência
}

\author{
Laura Muller Machado ${ }^{*} \dagger$ \\ Luiz Guilherme Dácar da Silva Scorzafave ${ }^{\ddagger}$
}

\author{
Sumário: 1. Introdução; 2. Revisão de Literatura; 3. Metodologia; 4. Resultados; 5. Conclusão. \\ Palavras-chave: Análise no Quantil, Salário, Professores. \\ Códigos JEL: I21, I25, J31.
}

Estudar a estrutura de remuneração de um país é importante por várias razões. Talvez uma das principais seja porque a remuneração pode afetar a atratividade da carreira e a habilidade dos profissionais que exercem a função de professor. O presente trabalho buscou comparar a diferença do salário-hora entre professores e não professores graduados em carreiras tipicamente relacionadas à profissão docente: Ciências da Educação, Formação de Professores, Língua Materna, Matemática, Biologia e Química. O objetivo era entender como profissionais recém-graduados escolheram diferentes ocupações (docente versus não docente) levando ao aparecimento de um diferencial salarial importante já nos primeiros anos de vida profissional. Desta análise, sob a hipótese de ignorabilidade e a hipótese de preferências semelhantes antes do ingresso no ensino superior corretamente especificadas, pode-se concluir que aqueles que exercem a profissão de professor, tanto na média, quanto no quantil 10 e na mediana, possuem um diferencial de salário hora positivo com relação aos que não são docentes. Já no quantil 90, não há diferença de salário entre os grupos. Os resultados mostram também que a diferença é explicada majoritariamente pelo retorno às características que determinam o salário e menos por diferenças nos níveis de tais características. Existem duas implicações desses resultados. Primeiro, considerando-se salário como proxy para habilidade, pode-se inferir que os professores já são os mais habilidosos da amostra analisada. Sendo assim, aumentar o salário dos docentes não atrairia profissionais mais habilidosos para a

\footnotetext{
*Universidade de São Paulo, Faculdade de Economia Administração e Contabilidade de Ribeirão Preto (USP/FEA-RP). Email: laurammachado@gmail.com

${ }^{\dagger}$ Fundação Lemann.

${ }^{\ddagger}$ Universidade de São Paulo, Faculdade de Economia Administração e Contabilidade de Ribeirão Preto (USP/FEA-RP). Avenida dos Bandeirantes, 3900, Bloco C. Monte Alegre, Ribeirao Preto, SP, Brasil. CEP 14040-900. Email: scorza@usp.br
} 
profissão, dentro das carreiras estudadas, pois já são os profissionais mais habilidosos que são docentes. Uma alternativa seria capacitar esses profissionais de forma a aumentar a habilidade destes. Segundo, outra forma de aumentar a habilidade dos professores seria compreender como esse diferencial salarial afeta a decisão de ingresso na carreira docente, e buscar atrair profissionais mais habilidosos para o magistério antes da escolha da carreira a ser cursada no ensino superior. Isso poderia possibilitar que indivíduos com maior habilidade se interessassem pelo magistério. Em ambos os casos, para que seja efetivo para a geração de capital humano, um aumento salarial do cargo de professor deve estar atrelado à criação de condições para o aumento da habilidade dos profissionais que ocupam tal posição.

This study aims to compare the wage gap between teachers and non-teachers in careers typically related to the teaching profession (Biology, Mathematics, Linguistics and Pedagogy). The objective is to understand the factors associated with the higher wages of teachers for profissionals aged 18 to 27. The results suggest the existence of a wage differential favoring teachers, both in average and also in quantiles 10 and 50 in 2010. In quantile 90, we do not find wage gap between teachers and nonteachers. The differentials are mainly explained by differences in returns associated to characteristics that determine wages. For instance, in quantile 50, to be a public sector employee is associated with a higher wage for teachers than for non-teachers. On the other hand, a very small fraction of the differential is associated with different composition of the teacher and non-teacher groups. Differences in coefficientes regarding region or residence and city population size are the only factors that individually explain the wage gap for those in quantiles 10 and 50.

\section{INTRODUÇÃO}

Muitos estudos mostram que a qualidade da educação impacta positivamente os salários futuros dos indivíduos e o crescimento econômico do país, conforme mostram, por exemplo, Kimko \& Hanushek (2000) e Bishop (1989). Por sua vez, o Brasil apresenta um baixo desempenho educacional quando comparado a outros países. Por exemplo, na avaliação PISA (Programme for International Student Assessment), um dos principais exames aplicado a vários países para avaliar a qualidade educacional de jovens de 15 anos, o Brasil apresentou uma das menores pontuações entre 65 países, ficando em $57^{\circ}$ lugar no ano de 2012. Buscando propostas de melhoria para a educação Barber \& Moushed (2007) observam que os 10 países com as melhores notas no PISA diferem em alguns pontos dos outros participantes. Nesse grupo de países, um fato que se destaca é que os professores possuem salários tão bons ou melhores que o de outras profissões prestigiadas.

Outros estudos também ressaltam que a estrutura de remuneração dos professores de um país precisa ser averiguada de modo relativo a de outras ocupações, pois a remuneração pode afetar as decisões dos indivíduos em diferentes dimensões. Primeiro, a remuneração pode afetar a decisão dos individuos mais bem qualificados de se tornarem professores. Segundo, dado que o professor ingressou na profissão docente, ela pode afetar o esforço que será exercido em sala de aula. Por fim, pode desistimular (ou não) a rotatividade desses profissionais nas escolas.

Nesse sentido, o objetivo desse trabalho é investigar quais são os fatores associados ao diferencial de salários entre professores e não-professores no Brasil. Especificamente, escolhemos trabalhar apenas com profissionais graduados em carreiras cuja maioria dos formados tipicamente acaba ingressando na docência. Uma hipótese subjacente a essa escolha é que as preferências desses indivíduos pela carreira docente antes do ingresso no ensino superior eram semelhantes. Dito de outro modo, uma vez optando 
por uma dessas carreiras, os indivíduos saberiam que teriam uma probabilidade alta de se tornarem docentes.

Assim, será investigado o diferencial de salário entre professores e não professores recém formados para compreender se: a) existe uma eventual menor remuneração relativa dos professores; b) que fatores estariam associados a esse diferencial salarial. Por fim, cabe destacar que o fato de a literatura apontar a existência de uma relação entre o salário relativo dos professores e a proficiência dos alunos também justifica a importância do presente estudo.

Apesar de já existirem trabalhos para o Brasil associando o diferencial de salários de professores e não professores, esse trabalho inova em três direções. Primeiro, trabalhamos com recém graduados de carreiras tipicamente ligadas à docência. Assim, será investigado se esses profissionais, ao ingressarem na ocupação docente, ganham menos do que seus pares de mesma formação acadêmica. Segundo, ao trabalharmos com pessoas de até 27 anos, é possível associar a formação em nível superior com a escolha ocupacional e os salários na fase inicial da carreira profissional. Desse modo, embora não seja nosso objetivo identificar uma relação causal entre salários e escolha ocupacional, ao restringir a análise a essa faixa etária, haveria menor interferência de fatores como experiência prévia no mercado de trabalho nos diferenciais salariais. Por fim, realizamos a decomposição do diferencial salarial entre docentes e não docentes de acordo o método proposto por Firpo, Fortin \& Lemieux (2009) que possibilita analisar diferentes quantis da distribuição salarial.

\section{REVISÃO DE LITERATURA}

Recentemente a UNESCO lançou uma exposição intitulada "A Educação Conta", a qual destaca que a educação ajuda a combater a pobreza e capacita as pessoas com conhecimento e habilidades que precisam para construir um futuro melhor. De acordo com o trabalho, um ano extra de escolaridade nos países em desenvolvimento aumenta a renda individual em até $10 \%$ e a taxa de crescimento do PIB em $0,37 \%$. Além disso, 171 milhões de pessoas poderiam sair da pobreza se todos os estudantes em países em desenvolvimento deixassem a escola sabendo ler. Outra evidência da importância da educação para o crescimento é o resultado de Kimko \& Hanushek (2000) que mostra que um aumento de um desvio padrão da qualidade da força de trabalho gera um aumento da taxa de crescimento da renda per capita de 1,4 pontos percentuais.

Apesar dessa importância ser largamente comprovada e analisada na literatura, a situação educacional no Brasil é crítica quando comparada a outros países. No PISA, o Brasil apresentou uma média de 391 pontos em matemática, ficando em $57^{\circ}$ lugar entre 65 países (OECD, 2012). Mesmo em comparação a outros países da América Latina, Menezes-Filho (2001) mostra, por exemplo, que apesar da melhoria educacional apresentada nos últimos 20 anos, a evolução da educação brasileira foi mais lenta que a dos outros países latino-americanos.

Uma possível estratégia para tentar compreender essa situação brasileira é focar em um dos fatores que, segundo Hanushek (1986), mais explicam a diferença de desempenho entre os alunos: a qualidade dos professores. Esse autor mostra que a habilidade do professor é muito mais importante na formação de capital humano do que uma série de outros fatores.

No entanto, entender a formação de habilidades é uma tarefa complexa. Assim, será discutido como a literatura tem se utilizado do salário como um dos principais fatores determinantes na seleção de professores de maior habilidade.

\subsection{Salários, habilidade dos professores e desempenho dos alunos}

Em estudo feito nos Estados Unidos com dados dos anos de 1969, 1979 e 1989, Stoddard (2003) encontrou evidências de que o salário é importante na determinação da qualidade dos professores. 0 estudo encontrou que o aumento do salário dos não professores tem impacto negativo na qualidade dos professores. Ainda analisando dados dos Estados Unidos e a qualidade dos professores ao longo do 
tempo, Lakdawalla (2006) mostra que a qualidade dos professores declinou de 1940 a 1990 . Segundo o autor, isso se deve principalmente ao aumento do salário de trabalhadores com alta habilidade, fazendo com que as escolas diminuíssem a contratação desses profissionais.

Ambos estudos sugerem que a habilidade dos professores está diretamente relacionada aos salários ofertados a esses profissionais. Dado que o principal insumo da função de produção de educação são professores de alta qualidade, é importante analisar como variações de salários estão associadas a escolha ocupacional, particularmente entre os profissionais mais habilidosos.

Em estudo com dados de 1960 à 1990 dos Estados Unidos e analisando apenas as professoras, foram encontradas evidências de que quanto mais bem pagas em relação a outros profissionais, maior a probabilidade de mulheres jovens altamente habilidosas escolherem ser professoras. 0 estudo de Bacolod (2006) conclui que $10 \%$ de aumento no salário alternativo (não professores) gera $6,4 \%$ de queda na probabilidade das mais hábeis virarem professoras e 3,5\% de queda das menos hábeis. Ou seja, variações de salários são mais sensíveis para os profissionais mais habilidosos.

Além da habilidade, um outro ponto importante que afeta a qualidade dos professores é o tempo de experiência na profissão. A maior experiência permite ao professor lidar melhor com os alunos em sala de aula e desenvolver habilidades tácitas fundamentais para uma melhor performance. Analisando dados de professores que abandonaram a profissão, Gilpin (2011) mostra que o efeito de aumento de salário fora da docência é significante apenas para aqueles com poucos anos de profissão. Para os mais experientes esse efeito não foi encontrado. Se a hipótese de que alta rotatividade é prejudicial aos alunos for válida esse resultado é importante. Resultado semelhante é obtido por Imazeki (2005) que mostra que aumentar o salário inicial evita que professores-iniciantes abandonem a profissão, enquanto que aumentar o salário de professores mais experientes não tem esse mesmo efeito.

Em suma, os estudos com dados dos Estados Unidos mostram que o salário relativo dos docentes está diretamente associado à atratividade da carreira docente, especialmente para profissionais de alta habilidade. Esses são os mais sensíveis a alterações salariais, abandonando a profissão com mais facilidade frente a uma queda do salário relativo, particularmente no início da carreira.

Também existem evidências da relação entre aumentos de salário e desempenho dos alunos na América Latina. Por exemplo, no Chile, o SNED (Sistema Nacional de Evaluatión de Desempeño de los Estabelecimientos Educacionales), criado em 1996, permite ajustes dos salários dos professores da rede pública de acordo com o desempenho da escola. Mizala \& Romaguera (2004) encontraram resultados positivos do SNED sobre o desempenho dos alunos, principalmente nas escolas de menor qualidade. Além disso, o salário real dos professores aumentou 156\% entre 1992 e 2002, sendo maior que o salário de outras profissões que requeriam diploma. No mesmo período, o número de estudantes da área da educação aumentou 39\%. Esses dados revelam dois fatores importantes: primeiro, que a política salarial é relevante para a atração de bons profissionais de ensino; segundo, que gera impacto positivo no capital humano.

O governo brasileiro também vem realizando reformas que possibilitam o aumento do salário dos professores. O FUNDEF implantado em 1998 pelo governo federal, teve como objetivo distribuir recursos federais entre estados e municípios para aumento dos salários de professores. Foi estabelecido que $60 \%$ dos recursos educacionais deveriam ir para desenvolvimento da educação fundamental e o programa estabelece um piso de gasto por aluno. No Brasil, Menezes-Filho \& Pazello (2007) usando dados do FUN$\mathrm{DEF}$, encontram que a proficiência dos alunos da escola pública é positivamente impactada pelo salário dos professores, especialmente os das regiões mais carentes. Esse resultado é similar ao encontrado por Mizala \& Romaguera (2004) no programa do Chile.

Como o salário relativo dos docentes em comparação aos não docentes pode afetar tanto a qualidade média do professor quanto a proficiência dos alunos, é importante investigar o diferencial salarial entre esses dois grupos. 


\subsection{Comparação de salário de professores e não professores}

O estudo de Mizala \& Romaguera (2004) analisa a diferença da estrutura de salário de professores e não professores no Chile utilizando a decomposição de Oaxaca-Blinder. Os resultados mostram que tanto os professores possuem melhores níveis de atributos que levam a maiores salários, como esses atributos são mais valorizados para os professores do que para outras categorias.

Em trabalho similar, Moriconi \& Marconi (2008) estudaram o diferencial salarial dos professores do Brasil comparando-os com os seguintes grupos: demais ocupações do setor público, professores do setor privado e demais ocupações do setor privado. Segundo os autores, os salários dos professores da rede pública são mais atrativos para profissionais com nível médio completo de escolaridade do que para os com nível superior. Ainda segundo os autores os professores da rede pública brasileira com nível superior ganharam menos do que receberiam se pertencessem a qualquer um dos grupos de comparação.

Em estudo similar, com os dados da PNAD de 2006, Becker (2008) inclui na análise o fato de que os professores têm o benefício de se aposentar cinco anos antes dos outros profissionais com aposentadoria integral. Com isso, o diferencial de remuneração em relação a outras ocupações diminui significativamente. Observou-se que os professores do ensino fundamental possuem menor remuneração em comparação aos profissionais da ciência. Em comparação aos trabalhadores da produção e serviços, os professores obtém um rendimento superior.

Para analisar o diferencial quantílico da avaliação chilena do SNED, Juhn, Murphy \& Pierce (1993) estimam os diferenciais de salários para os diferentes quantis da distribuição condicional de salário. Os autores interpretaram a posição na distribuição do logaritmo de salário como medida de habilidade não observada. Ou seja, salários maiores seriam uma proxy para habilidades não observadas dos indivíduos. Segundo os autores, o diferencial condicional de salários tende a ser favorável para professores de menor habilidade (que estão na parte inferior da distribuição de salários); por sua vez, o diferencial tende a ser zero ou negativo para professores muito hábeis (na parte superior da distribuição). Na média, depois que as diferenças de características são consideradas, professores no percentil 10 recebem salários 60\% maiores do que seus contra-partes no mesmo percentil, professores do percentil 25 recebem $43 \%$ mais e professores no percentil 50 recebem $24 \%$ mais. Na outra ponta da distribuição, professores do percentil 75 recebem salários pelo menos tão bons quanto não professores. Professores no percentil 90 recebem salários $14 \%$ menores. Dessa forma, professores com menor habilidade tem uma remuneração relativamente melhor quando escolhem ser professores ao invés de outras profissões. Já os professores de maior habilidade recebem menor remuneração quando comparados a outras profissões.

Portanto, fica clara a existência de uma lacuna na literatura brasileira acerca do diferencial salarial de professores e outras ocupações, pois não há estudo que procure analisar essa questão em diferentes partes da distribuição salarial. Desse modo, o presente artigo é o primeiro que busca realizar uma decomposição desse diferencial ao longo dos quantis da distribuição salarial.

\section{METODOLOGIA}

No Brasil não existe uma qualificação específica para exercer a profissão de professor. Conforme determinação do Governo Federal o profissional precisa ter ensino superior com licenciatura ou ser formado em pedagogia. Ou seja, os potenciais professores poderiam exercer outra profissão sem grandes restrições. Pode-se pensar que a decisão de se tornar professor (ou não) segue a lógica de um modelo de escolha em que o indivíduo compara a utilidade esperada ao longo do ciclo de vida das duas alternativas. Essa utilidade depende tanto de fatores pecuniários como dos não pecuniários percebidos pelo indivíduo. A escolhar é feita com base na alternativa que gera a maior utilidade. Na prática, raramente é factível estimar essa utilidade, pois a estimação requer hipóteses sobre taxa interna de retorno, horizonte de tempo, entre outros. Conforme Brewer (1996), devido à essas dificuldades, na maioria dos artigos, a utilidade é medida simplesmente como o salário. Contribui nessa decisão o fato de que, geralmente, os fatores não pecuniários são de difícil observação. 
Um dos possíveis fatores não monetários que afetam essa decisão é a vocação. A vocação profissional é formada por um conjunto de aptidões naturais e interesses específicos do indivíduo que o direcionam na escolha de uma profissão. Ou seja, se admitirmos que existem indivíduos que tem aptidão para ser professor, provavelmente a escolha do curso superior será direcionada visando o objetivo de exercer a profissão de professor. Analisando os dados do Censo Demográfico de 2010, os professores do ensino fundamental tem, em sua maioria, graduação nos cursos superiores listados na Tabela 1.

Tabela 1. Frequência de graduação entre professores.

\begin{tabular}{lc}
\hline \multirow{2}{*}{ Ensino Superior } & $\begin{array}{c}\text { Representação entre professores } \\
(\%)\end{array}$ \\
\hline Ciências da Educação & 38,8 \\
Formação de professores & 18,3 \\
Língua materna & 12,8 \\
Matemática & 4,9 \\
Biologia e Química & 2,8 \\
\hline Total & 77,6 \\
\hline
\end{tabular}

Assim, 78\% dos docentes cursou uma dessas cinco graduações. Se analisarmos cada graduação separadamente, cerca de $71 \%$ dos formados em 2010 de cada uma delas não estava trabalhando como professores. Portanto, ao escolher uma dessas carreiras a probabilidade a priori de um indivíduo vir a exercer a ocupação de professor não é muito elevada.

\subsection{Dados}

Os dados utilizados no trabalho são oriundos do Censo Demográfico 2010, coletados pelo Instituto Brasileiro de Geografia e Estatistística (IBGE). Particularmente, utilizamos os dados do estado de São Paulo com trabalhadores que estavam empregados no momento da pesquisa e que declararam o salário e a ocupação. Foram considerados os funcionários públicos das esferas federal, estadual e municipal e trabalhadores com carteira assinada. Serão considerados apenas trabalhadores com ensino superior nos cursos de Ciências da Educação, Formação de Professores Específico, Formação de Professores de Disciplinas Profissionais, Língua Materna, Matemática, Biologia e Química ${ }^{1}$.

A amostra será restrita aos profissionais de 18 a 27 anos para focarmos a análise do mercado de trabalho dessas pessoas no período imediatamente após a conclusão do curso superior. De certa forma procura-se restringir a análise a profissionais que ainda não trocaram de ocupação desde sua graduação. As variáveis explicativas utilizadas na análise serão baseadas no trabalho de Becker (2008) e de Chevalier, Dolton \& McIntosh (2007) pois ambos estudos, apesar de utilizarem metodologias diferentes, buscavam estudar e responder perguntas similares ao presente estudo. As variáveis são as seguintes: idade, cor, sexo, condição na família, escolaridade, tipo de ocupação (funcionário público ou não) e área de graduação. Serão incluídas variáveis geográficas disponibilizadas no Censo Demográfico referentes à região administrativa em que o indivíduo mora e se o município de residência possui mais de 150 mil habitantes. A variável dependente do modelo é o salário por hora trabalhada.

\subsection{Modelo de decomposição}

O método propõe uma aproximação linear para um funcional da distribuição. O funcional é obtido através da função influência que é definida como a influência de uma observação na distribuição da

${ }^{1}$ Códigos 142, 145, 146, 223, 461, 421 da tabela de códigos de cursos superiores do Censo Demográfico. 
estatística de interesse. A função influência é largamente utilizada para estimações robustas, podendo ser facilmente computada para qualquer quantil. Será apresentado o método para qualquer estatística de interesse $v$, porém, para este trabalho, $v$ será sempre quantis salariais.

Definimos a Recentered influence function, RIF, como

$$
\operatorname{RIF}(y, v)=v(F)+\mathbb{F}(y ; v) .
$$

Temos por definição que

$$
\int_{-\infty}^{\infty} \mathbb{F}(y ; v, F) \mathrm{d} F(y)=0 .
$$

No caso dos quantis, a função influência é dada por

$$
\mathbb{F}\left(Y, Q_{\tau}\right)=\frac{\tau-\Pi\left\{Y \leq Q_{\tau}\right\}}{f_{Y}\left(Q_{\tau}\right)} .
$$

Seja $Q_{\tau}$ o $\tau$-ésimo quantil da distribuição não condicional de $Y$; $\Pi(\cdot)$ uma função indicadora de quando a variável resposta é maior ou igual ao quantil $Q_{\tau}$; e $f_{Y}(\cdot)$ a densidade marginal da distribuição de $Y$. Como resultado, a RIF pode ser reescrita como

$$
\begin{aligned}
& \operatorname{RIF}\left(Y, Q_{\tau}\right)=Q_{\tau}+\frac{\tau-\Pi\left\{Y \leq Q_{\tau}\right\}}{f_{Y}\left(Q_{\tau}\right)} \\
& \operatorname{RIF}\left(Y, Q_{\tau}\right)=c_{1, \tau} \Pi\left\{Y>Q_{\tau}\right\}+c_{2, \tau},
\end{aligned}
$$

onde $c_{1, \tau}=1 / f_{Y}\left(Q_{\tau}\right)$ e $c_{2, \tau}=Q_{\tau}-c_{1, \tau}(1-\tau)$. Multiplicado pelas constantes $c_{1, \tau}$ e $c_{2, \tau}$ a função influência recentrada é simplesmente uma indicadora de quando a variável resposta é maior ou igual ao quantil $Q_{\tau}$. Assim, utilizando a lei das expectativas iteradas, a estatística genérica de interesse $v$ pode ser expressa como função da RIF condicional. O modelo irá estimar uma regressão linear de $\Pi\left\{Y \leq Q_{\tau}\right\}$ em $X$. A expectativa da função RIF é dada por

$$
\begin{aligned}
\int \operatorname{RIF}(y ; v, F) \mathrm{d} F(y) & =\int(v(F)+\mathbb{F}(y, v)) \mathrm{d} F(y)=v(F) \\
v(F(y)) & =\int \operatorname{RIF}(y ; v, F) \mathrm{d} F(y) \\
& =\iint \operatorname{RIF}(y ; v, F) \mathrm{d} F\left(y_{y} \mid X\right)(y \mid X=x) \mathrm{d} F_{X}(x) \\
& =\int \mathbf{E}[\operatorname{RIF}(y ; v, F) \mid X=x] \mathrm{d} F_{X}(x) .
\end{aligned}
$$

Sabemos que $\mathrm{E}[\operatorname{RIF}(y ; v, F) \mid X=x]$ é facilmente calculada usando regressão linear. Essa imposição de linearidade da função tem como objetivo facilitar o desenvolvimento da estimação e é comumente utilizada na literatura. Sejam as estruturas salariais definidas pelos professores do ensino público fundamental como grupo $1(t=1)$ e das demais profissões como grupo $0(t=0)$. Podemos rearranjar a função (9) da forma que segue:

$$
m_{t}^{v}(x)=\mathrm{E}\left[\operatorname{RIF}\left(y_{t} ; v_{t}, F\right) \mid X=x, T=t\right] .
$$

Para encontrar a estatística genérica de interesse $v$ para professores $(t=1)$ ou para não professores $(t=0)$ temos, com as equações acima, que os momentos das distribuições serão

$$
\begin{aligned}
& v_{1}=\mathbf{E}\left[m_{1}^{v} \mid T=1\right], \\
& v_{0}=\mathbf{E}\left[m_{0}^{v} \mid T=0\right] .
\end{aligned}
$$


Podemos então fazer a decomposição Oaxaca-Blinder para outros momentos da distribuição. Seguindo a idéia básica de Oaxaca (1973), são computadas separadamente as equações mincerianas para professores e não professores. Com estas equações, calcula-se os rendimentos contra-factuais dos professores no caso deles serem remunerados como os não professores. Isto é, transfere-se os coeficientes da equação dos professores para os não professores. Nesse caso, o efeito da estrutura salarial, $\Delta_{s}^{v}$, e o efeito composição, $\Delta_{c}^{v}$, podem ser escritos apenas rearranjando as equações descritas acima:

$$
\begin{aligned}
& \Delta_{s}^{v}=\mathbf{E}\left[m_{1}^{v} \mid T=1\right]-\mathbf{E}\left[m_{C}^{v} \mid T=1\right], \\
& \Delta_{c}^{v}=\mathbf{E}\left[m_{C}^{v} \mid T=1\right]-\mathbf{E}\left[m_{0}^{v} \mid T=0\right] .
\end{aligned}
$$

onde $m_{t}^{v}(x)=x^{T} \gamma_{t}^{v}$ é a equação (10) para professores e não professores e $m_{C}^{v}(x)=x^{T} \gamma_{C}^{v}$ é a mesma função para o grupo contra-factual. Podemos reescrever $\Delta_{s}^{v}$ e $\Delta_{c}^{v}$ conforme segue:

$$
\begin{aligned}
& \Delta_{s}^{v}=\mathbf{E}[X \mid T=1]^{T}\left(\gamma_{1}^{v}-\gamma_{C}^{v}\right), \\
& \Delta_{c}^{v}=\mathbf{E}[X \mid T=1]^{T} \gamma_{C}^{v}-\mathbf{E}[X \mid T=0]^{T} \gamma_{0}^{v} .
\end{aligned}
$$

As equações acima podem generalizar a decomposição Oaxca-Blinder para qualquer estatística de distribuição através da projeção da função influência recentrada. Para o caso dos quantis, Firpo et al. (2009) mostra que a melhor forma para fazer as estimações é primeiramente calcular os quantis amostrais e em seguida estimar a densidade do ponto através dos métodos de kernel. A estimativa da RIF de cada observação é obtida associando as estimativas de $Q_{\tau} \operatorname{com} F\left(Q_{\tau}\right)$, ou seja, os elementos detalhados dos efeitos composição e estrutura são computados da mesma forma que a média. Dessa forma, será utilizada uma equação correspondente a decomposição Oaxaca-Blinder e os coeficientes serão dados por

$$
\begin{aligned}
& \gamma_{t}^{v}=\left(\mathrm{E}\left[X X^{T} \mid T=t\right]\right)^{-1} \mathrm{E}\left[\operatorname{RIF}\left(Y_{t} ; v_{t}\right) X \mid T=t\right], \\
& \gamma_{C}^{v}=\left(\mathrm{E}\left[X X^{T} \mid T=1\right]\right)^{-1} \mathrm{E}\left[\operatorname{RIF}\left(Y_{0} ; v_{C}\right) X \mid T=t\right] .
\end{aligned}
$$

\section{RESULTADOS}

Na metodologia de decomposição do diferencial salarial entre professores e não professores, essa diferença pode estar associada aos efeitos estrutura e composição. Desse modo, nessa seção, será inicialmente apresentada uma análise descritiva na qual, para cada variável explicativa, será comparada a distribuição salarial de professores e não professores. Assim, será possível saber se, por exemplo, entre as mulheres, as professoras ganham mais que as não professoras. Em seguida, será analisada a diferença na composição dos grupos de professores e não professores em termos das seguintes variáveis (região de residência, tamanho do município, tipo de graduação, posição no domicílio, idade, cor da pele, sexo e se a pessoa estava no setor público). A ideia é saber se, por exemplo, há maior preponderância de mulheres entre professores do que entre os não professores. Em seguida, será apresentada a estimação da equação de salários por mínimos quadrados ordinários, a decomposição de Oaxaca-Blinder e, por fim, a decomposição quantílitica para os percentis 10, 50 e 90.

\subsection{Análise descritiva}

A amostra aqui utilizada possui 7.107 observações, sendo 2.101 professores e 5.006 não professores. A primeira variável a ser analisada é a variável dependente do modelo, o salário por hora. Conforme mostra a Tabela 2 o salário horário dos professores é, em média, $\mathrm{R} \$ 1,46$ maior do que o de outras ocupações, sendo esta diferença estatisticamente significativa. Observa-se também que o desvio padrão do salário de não professores é elevado, provavelmente devido ao fato de que há uma heterogeneidade grande nas ocupações dos profissionais desta categoria. 
Tabela 2. Análise descritiva dos salários por hora de trabalho.

\begin{tabular}{lccccr}
\hline Variável & Ocupação & Média & Desvio-padrão & Máximo & Mínimo \\
\hline \multirow{2}{*}{ Salário/hora ${ }^{* *}$} & Professor & 12,13 & 11,87 & 0,88 & 140,63 \\
& Não Professor & 10,67 & 25,57 & 0,18 & $1.250,00$ \\
\hline
\end{tabular}

** Diferença significativa com teste bicaudal de valor $95 \%$.

Figura 1. Distribuição do salário hora de professores e não professores (em ln).

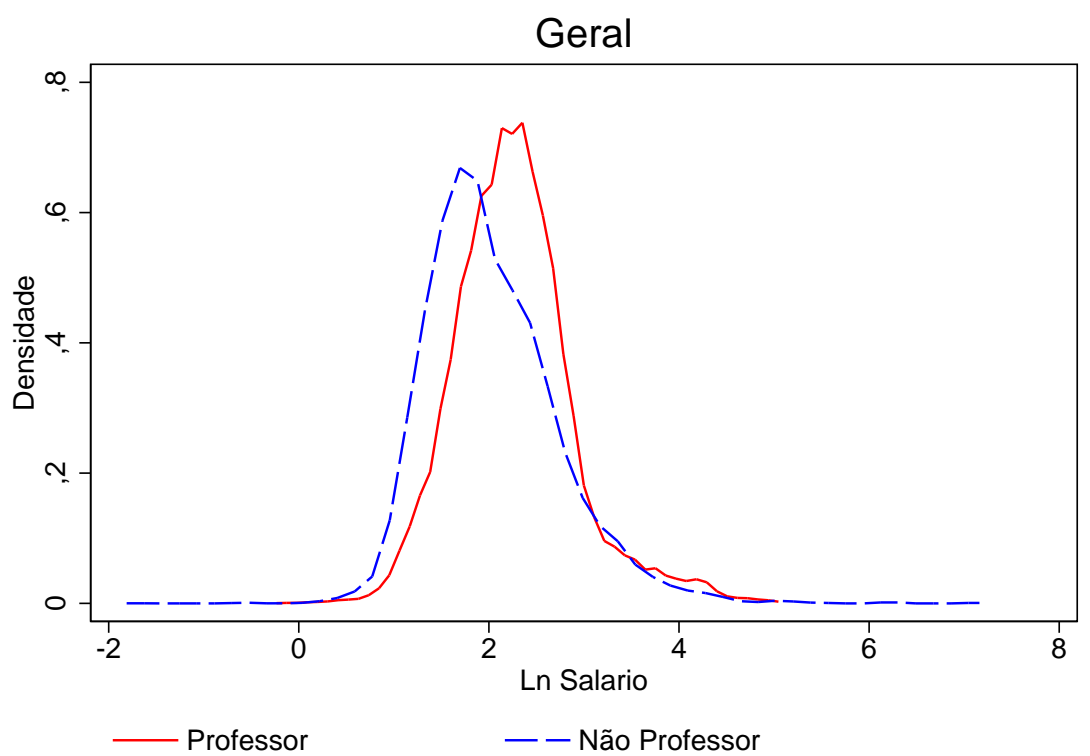

Já a Figura 1 apresenta as densidades de probabilidade dos salários de professores e não professores para o logaritmo do salário por hora sem condicionarmos a nenhum dos regressores. De modo geral, para quase toda a distribuição, os professores possuem maior salário horário do que os não professores, já que a distribuição salarial de não professores está praticamente toda deslocada à direita relativamente a de não professores (até pelo menos o percentil 90 de cada uma delas). Apenas a cauda superior da distribuição de salários (acima do percentil 99) apresenta maiores valores de salários para os não professores.

Para embasarmos a discussão posterior sobre a análise de decomposição, realiza-se agora a apresentação do diferencial salarial entre professores e não professores, condicional nas variáveis explicativas. A ideia aqui é averiguar se a tendência de maiores ganhos salariais de professores ocorre também dentro de cada categoria e em diferentes partes da distribuição salarial.

Assim, para cada grupo de características (sexo, faixa etária, tipo de graduação, chefe de domicílio, cor de pele, região do estado onde mora e tamanho do município), foi realizado o teste de KolmogorovSmirnov para avaliar a diferença da distribuição salarial entre professores e não professores dentro de cada um desses grupos. Em todos os casos, se concluiu que a distribuição salarial de professores e não professores era diferente. Esse fato indica a necessidade de se considerar essas variáveis no exercício de decomposição salarial. ${ }^{2}$ Apresentamos na Figura 2 para algumas dessas variáveis, mas o perfil é bastante semelhante nos demais casos.

\footnotetext{
${ }^{2}$ Além disso, como não se encontrou diferença de salário médio entre professores e não professores dentro de diversos grupos (homens, não brancos, com idade até 24 anos, chefes de família, não funcionários públicos, licenciados em Matemática ou Letras e residentes nas regiões de São Paulo ou Campinas), se reforça a importância de se analisar toda a distribuição salarial.
} 
Figura 2. Distribuição do salário hora de professores e não professores por diferentes características.
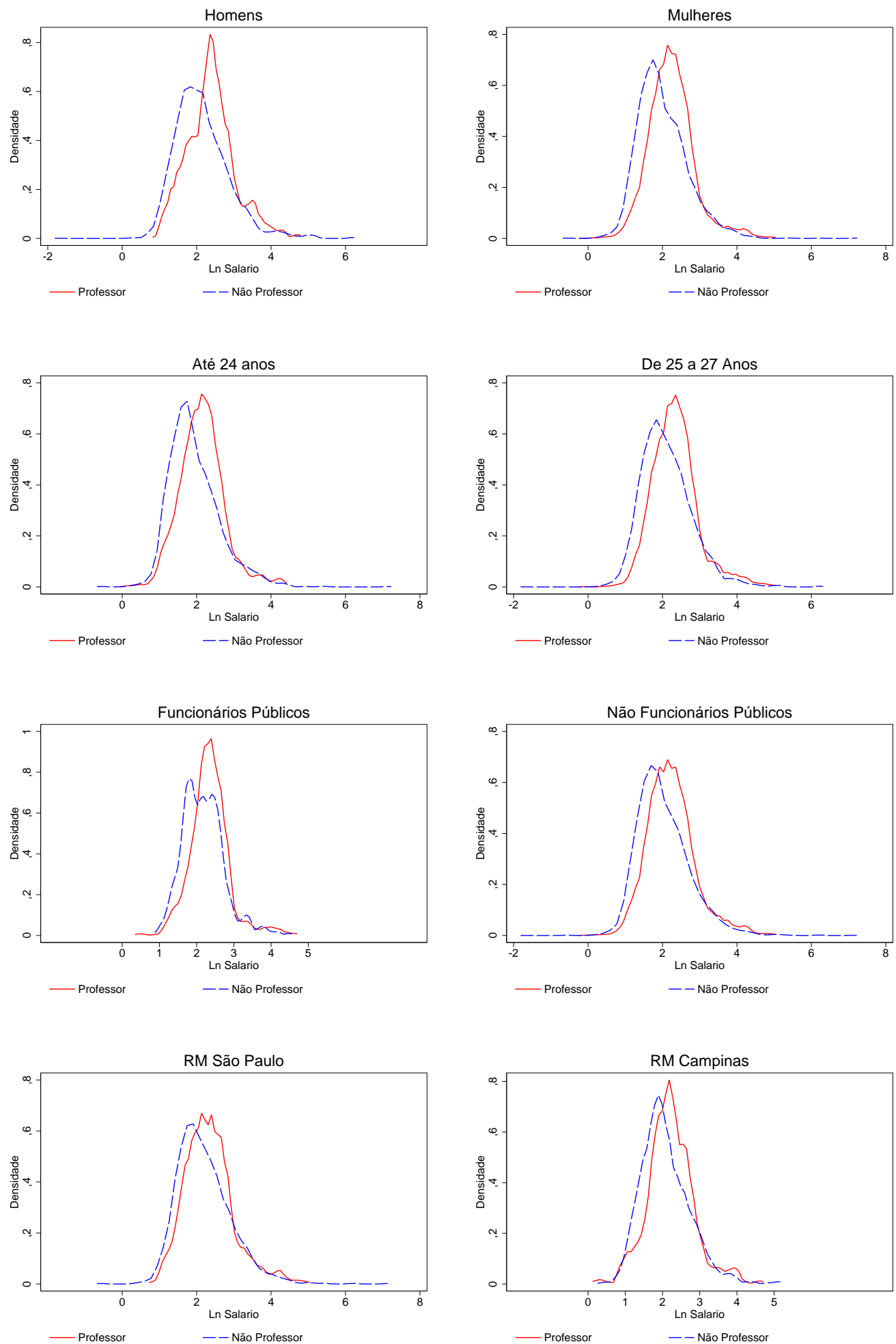
No caso das mulheres, a distribuição salarial das professoras está claramente mais deslocada à direita do que a de não professoras, de modo muito semelhante à distribuição geral (o que era esperado dado que as mulheres correspondem a mais de $75 \%$ da nossa amostra).

Já para os gráficos por idade, tanto para aqueles com até 24 anos como para os com 24 a 27 anos, os professores têm maiores salários que os não professores. Isso também se verifica para os casos de trabalhadores que sejam (ou não) funcionários públicos, vale para todas as áreas de formação superior, independe do porte do município e da região do estado de São Paulo onde os indivíduos residem. Em cada um desses recortes, os professores sempre ganham mais que os não professores com um mesmo atributo. Assim, a decomposição permitirá analisar se essas diferenças se mantém após considerarmos os demais fatores observados.

Também foi analisado como indivíduos com diferentes características se distribuem entre professores e não professores. Apresenta-se também o teste bicaudal de igualdade dessas proporções. Entre os não professores há uma fração maior de homens (25\%) que entre professores (15\%) e esta diferença é estatisticamente significativa. Em ambos os grupos apenas $16 \%$ são chefes de família, o que é esperado dado que a amostra compreende indivíduos entre 18 e 27 anos. Não há diferença na composição dos grupos por cor da pele e idade.

Entre as variáveis de formação observa-se que metade da amostra de professores fez graduação em Ciências da Educação contra 38\% dos não professores; 16\% dos professores fez graduação em Línguas contra $11 \%$ de não professores. Cabe destacar que entre os não professores há maior parcela de graduados em formação específica para professores e em biologia do que entre os professores. As duas amostras têm $5 \%$ de indivíduos com graduação em matemática. Por fim, como esperado, há uma maior frequência de funcionários públicos entre professores (25\%) do que entre não professores (7\%), dado que as redes públicas de ensino são os principais demandantes dos profissionais da carreira docente.

Há uma concentração relativa de professores na região administrativa de São Paulo e, obviamente, uma maior concentração de não professores nas demais regiões do estado. Em termos de tamanho dos municípios, a distribuição dos profissionais das duas categorias é semelhante.

Em suma, em termos de diferenças na composição dos grupos, entre os professores há uma maior proporção de mulheres, eles estão mais concentrados na região de São Paulo e trabalham mais como funcionários públicos. Além disso a distribuição por tipo de formação superior é diferente entre professores e não professores. Já no que diz respeito a diferença na distribuição salarial, tanto de modo geral como dentro de cada grupo definido pelas variáveis acima descritas, a distribuição salarial de professores é diferente da de não professores, geralmente com os professores auferindo maiores salários horários em quase todos os percentis da distribuição.

\subsection{Estimação via mínimos quadrados ordinários}

São apresentados na Tabela 3 os coeficientes da estimação da equação de salários via mínimos quadrados ordinários. Observa-se que os coeficientes de professores e não professores são bastante distintos e, de forma geral, as variáveis significativas são diferentes para cada um dos grupos. Entre os não professores, os homens ganham em média $\mathrm{R} \$ 2,10$ por hora de trabalho a mais do que as mulheres. Essa diferença não é significativa entre os professores. Entre os professores, há um efeito da idade sobre o salário horário que não é verificado entre os não professores. Existe um diferencial de salário na média em favor dos professores brancos relativamente aos professores não brancos que também não se verifica entre os não professores.

Tanto para professores como para não professores não se verificou diferencial salarial por formações e o teste de significância conjunta não rejeita a hipótese nula de que a significância conjunta dessas variáveis seja zero. Em relação às variáveis geográficas, estar na região administrativa de São Paulo está associado a um maior salário para professores $(\mathrm{R} \$ 2,60)$ e não professores ( $R \$ 3,70)$, sendo este o fator que apresenta o maior coeficiente nas estimações. Residir em um municipio de mais de 150 mil habitantes está associado a maiores salários em ambas as categorias. 
Tabela 3. Descrição e análise descritiva das covariadas.

\begin{tabular}{|c|c|c|c|c|}
\hline Variável & Descrição & Professor & Não Professor & Teste de média \\
\hline Homem & $\begin{array}{c}\text { Sexo da pessoa } \\
(1=\text { Homem; } 0=\text { Mulher })\end{array}$ & 0,15 & 0,25 & $* *$ \\
\hline Idade & Idade da pessoa em anos & 24,79 & 24,54 & \\
\hline Cor branca & $\begin{array}{l}\text { Se declarou cor branca } \\
(1=\text { branca; } 0=\text { c.c.) }\end{array}$ & 0,79 & 0,79 & \\
\hline Chefe & $\begin{array}{l}\text { Responsável da unidade } \\
\text { familiar }\end{array}$ & 0,16 & 0,16 & \\
\hline Funcionário Público & $\begin{array}{l}\text { Se é funcionário público } \\
(1=\operatorname{Sim} ; 0=\text { Não })\end{array}$ & 0,25 & 0,07 & $* *$ \\
\hline Linguas & $\begin{array}{l}\text { Realizou graduação } \\
\qquad(1=\operatorname{Sim} ; 0=\text { c.c. })\end{array}$ & 0,16 & 0,11 & $* *$ \\
\hline Biologia & $\begin{array}{l}\text { Realizou graduação } \\
(1=\operatorname{Sim} ; 0=\text { c.c. })\end{array}$ & 0,05 & 0,15 & $* *$ \\
\hline Matematica & $\begin{array}{l}\text { Realizou graduação } \\
(1=\operatorname{Sim} ; 0=\text { c.c. })\end{array}$ & 0,05 & 0,05 & \\
\hline Educação & $\begin{array}{l}\text { Realizou graduação } \\
(1=\operatorname{Sim} ; 0=\text { c.c. })\end{array}$ & 0,50 & 0,38 & $* *$ \\
\hline Professor & $\begin{array}{l}\text { Realizou graduação } \\
\text { (1= Sim; } 0=\text { c.c.) }\end{array}$ & 0,23 & 0,31 & $* *$ \\
\hline Região de São Paulo & $\begin{array}{l}\text { Reside na região } \\
(1=\operatorname{Sim} ; 0=\text { c.c. })\end{array}$ & 0,48 & 0,41 & $* *$ \\
\hline Região de Campinas & $\begin{array}{l}\text { Reside na região } \\
(1=\operatorname{Sim} ; 0=\text { c.c. })\end{array}$ & 0,13 & 0,16 & $* *$ \\
\hline Mais de 150 mil habitantes & $\begin{array}{l}\text { Reside na região } \\
(1=\operatorname{Sim} ; 0=\text { c.c. })\end{array}$ & 0,59 & 0,58 & \\
\hline
\end{tabular}

${ }^{* *}$ Diferença significativa com teste bicaudal de valor $95 \%$. c.c. = caso contrário.

\subsubsection{Decomposição de Oaxaca-Blinder}

Conforme apresentado na metodologia, o modelo a ser aplicado neste trabalho é uma decomposição do tipo Oaxaca-Blinder para os quantis. Por isso, esta seção apresenta a decomposição de Oaxaca-Blinder tradicional. ${ }^{3}$ A Tabela 5 mostra o resultado da decomposição onde a especificação I utiliza os coeficientes dos professores como referência e na especificação II os coeficientes dos não professores são utilizados como referência.

Como vimos anteriormente, em média, os professores ganham $\mathrm{R} \$ 1,46$ a mais de salário por hora que os não professores. Apenas $13 \%$ dessa diferença é explicada pelas diferenças de características entre os dois grupos. O restante do diferencial se deve a diferenças dos coeficientes dos regressores das equações. No entanto, não é possível individualizar para que fator a diferença dos coeficientes seria mais importante para esse resultado. Ou seja, o resultado indica que, na comparação de professores e não professores jovens recém formados em graduações típicas da carreira docente, o diferencial salarial não está associada a uma composição diferente dos grupos, mas ao "retorno" dessas características. Esse

\footnotetext{
${ }^{3}$ Para maiores detalhes ver Oaxaca (1973).
} 
Tabela 4. Estimação de mínimos quadrados ordinários.

\begin{tabular}{lccccc}
\hline & \multicolumn{2}{c}{ Professor } & & \multicolumn{2}{c}{ Não professor } \\
\cline { 2 - 3 } \cline { 5 - 6 } Variável & Coeficiente & Erro padrão & & Coeficiente & Erro padrão \\
\hline Homem & 1,201 & $(1,024)$ & & $2,095^{* *}$ & $(1,098)$ \\
Idade & $0,496^{* *}$ & $(0,151)$ & & 0,215 & $(0,174)$ \\
Cor branca & $1,414^{* *}$ & $(0,735)$ & & 0,565 & $(0,992)$ \\
Chefe & $1,861^{* *}$ & $(0,830)$ & & 1,270 & $(1,128)$ \\
Funcionário Público & 0,095 & $(0,692)$ & & 0,068 & $(0,700)$ \\
Línguas & $-1,325$ & $(2,212)$ & & 2,896 & $(2,888)$ \\
Matemática & $-0,659$ & $(2,329)$ & & 1,485 & $(1,200)$ \\
Educação & $-2,094$ & $(2,256)$ & & 0,717 & $(0,893)$ \\
Professor & $-0,885$ & $(2,225)$ & & 1,168 & $(0,802)$ \\
Região de São Paulo & $2,612^{* *}$ & $(0,706)$ & & $3,688^{* *}$ & $(0,916)$ \\
Região de Campinas & 0,981 & $(0,769)$ & & $2,007^{* *}$ & $(0,632)$ \\
Mais de 150 mil habitantes & $1,097^{* *}$ & $(0,584)$ & & $2,092^{* *}$ & $(0,519)$ \\
Constante & $-2,315$ & $(4,409)$ & & 0,131 & $(4,031)$ \\
\hline
\end{tabular}

Notas: Estimação do erro padrão robusta para heterocedasticidade. Professores: $n=2.001, R^{2}=0,04$ e Prob $>F=$ 0,0. Não Professores: $n=5.006, R^{2}=0,01$ e Prob $>F=0,0$.

** Significância 5\%.

resultado é similar ao estudo de Mizala \& Romaguera (2004) para o Chile, que mostram que a diferença de salário favorece os professores em ambos os componentes, tanto no componente estrutura quanto no composição. Também é similar ao estudo de Becker (2008) que inclui a diferença previdenciária dos professores no Brasil e que aponta que a parte não explicada da decomposição é responsável pela maior parcela do diferencial. No entanto, nosso resultado é diferente do encontrado por Britto \& Waltenberg (2014) que se concentram em professores de ensino médio e utilizam como grupo de comparação para os professores todos os indivíduos com ensino superior. Apesar de os autores encontrarem diferencial salarial desfavorável aos professores, também concluem que a principal diferença também está na estrutura de remuneração.

\subsection{Decomposição quantílica}

As estimações da seção anterior mostram que a maior parte do diferencial se deve a diferenças na estrutura de remuneração dos dois grupos e que o diferencial é favorável, na média, para os professores. No entanto, a Tabela 6 mostra que o diferencial de salário varia ao longo da distribuição, sendo maior em torno da mediana e menor nos percentis 10 e 90, o que evidencia a importância de realizarmos uma análise de acordo com o quantis. Os resultados são alinhados com os de Juhn et al. (1993) sobre o diferencial quantílico do SNED, onde o diferencial de salários tende a ser positivo e maior para professores do grupo de menor salário e zero ou negativo para professores na parte superior da distribuição.

Será apresentada a decomposição da diferença salarial para os quantis 10,50 e 90 . No quantil 10, a diferença de salário é de $\mathrm{R} \$ 1,16$ por hora a favor dos professores. Apesar de tanto a parte explicada como a parte não explicada do diferencial serem significativas, $84 \%$ dessa diferença está associada à estrutura de remuneração, resultado semelhante ao obtido na decomposição de Oaxaca-Blinder tradicional. Na parte explicada, se igualássemos a proporção de funcionários públicos nos dois grupos o diferencial salarial cairia R\$0,14. No entanto, não é possivel identificar claramente os efeitos individuais da maior parte das variáveis. Por sua vez, se eliminássemos a diferença no retorno da variável relacionada a residir em cidades maiores de 150 mil habitantes, a diferença entre professores e não professores aumentaria adicionalmente em $\mathrm{R} \$ 0,41$. 
Tabela 5. Decomposição Oaxaca-Blinder para o Salário Horário Médio.

\begin{tabular}{|c|c|c|c|c|}
\hline \multirow[b]{2}{*}{ Variável } & \multicolumn{2}{|c|}{ Especificação I } & \multicolumn{2}{|c|}{ Especificação II } \\
\hline & Coeficiente & EP & Coeficiente & EP \\
\hline \multicolumn{5}{|l|}{ Diferencial } \\
\hline Predição Não Professores & $10,672^{* *}$ & $(0,421)$ & $10,672^{* *}$ & $(0,421)$ \\
\hline Predição Professores & $12,127^{* *}$ & $(0,321)$ & $12,127^{* *}$ & $(0,321)$ \\
\hline Diferença & $-1,455^{* *}$ & $(0,529)$ & $-1,455^{* *}$ & $(0,529)$ \\
\hline \multicolumn{5}{|l|}{ Parte explicada } \\
\hline Homem & $0,213^{* *}$ & $(0,113)$ & 0,122 & $(0,105)$ \\
\hline Idade & $-0,053$ & $(0,044)$ & $-0,122^{* *}$ & $(0,044)$ \\
\hline Cor branca & 0,003 & $(0,008)$ & 0,007 & $(0,015)$ \\
\hline Chefe & $-0,003$ & $(0,012)$ & $-0,005$ & $(0,018)$ \\
\hline Funcionário Público & $-0,012$ & $(0,123)$ & $-0,017$ & $(0,121)$ \\
\hline Educação & $-0,088$ & $(0,109)$ & 0,256 & $(0,277)$ \\
\hline Linguas & $-0,144$ & $(0,146)$ & 0,066 & $(0,111)$ \\
\hline Matematica & 0,002 & $(0,008)$ & $-0,001$ & $(0,005)$ \\
\hline Professor & 0,091 & $(0,064)$ & $-0,069$ & $(0,173)$ \\
\hline Mais de 150 mil habitantes & $-0,021$ & $(0,027)$ & $-0,011$ & $(0,015)$ \\
\hline Região de São Paulo & $-0,263^{* *}$ & $(0,081)$ & $-0,186^{* *}$ & $(0,061)$ \\
\hline Região de Campinas & $0,070^{* *}$ & $(0,028)$ & 0,034 & $(0,028)$ \\
\hline Total & $-0,206$ & $(0,205)$ & 0,073 & $(0,281)$ \\
\hline \multicolumn{5}{|l|}{ Parte não explicada } \\
\hline Homem & 0,134 & $(0,225)$ & 0,225 & $(0,377)$ \\
\hline Idade & $-6,973$ & $(5,711)$ & $-6,904$ & $(5,654)$ \\
\hline Cor branca & $-0,673$ & $(0,978)$ & $-0,677$ & $(0,984)$ \\
\hline Chefe & $-0,093$ & $(0,221)$ & $-0,092$ & $(0,217)$ \\
\hline Funcionário Público & $-0,007$ & $(0,242)$ & $-0,002$ & $(0,069)$ \\
\hline Educação & 1,418 & $(1,224)$ & 1,074 & $(0,927)$ \\
\hline Linguas & 0,683 & $(0,590)$ & 0,473 & $(0,408)$ \\
\hline Matematica & 0,098 & $(0,120)$ & 0,101 & $(0,123)$ \\
\hline Professor & 0,480 & $(0,554)$ & 0,639 & $(0,737)$ \\
\hline Mais de 150 mil habitantes & 0,590 & $(0,464)$ & 0,580 & $(0,456)$ \\
\hline Região de São Paulo & 0,518 & $(0,557)$ & 0,441 & $(0,475)$ \\
\hline Região de Campinas & 0,131 & $(0,128)$ & 0,167 & $(0,162)$ \\
\hline Constante & 2,446 & $(5,974)$ & 2,446 & $(5,974)$ \\
\hline Total & $-1,248^{* *}$ & $(0,611)$ & $-1,528^{* *}$ & $(0,619)$ \\
\hline
\end{tabular}

Notas: Estimação robusta para heterocedasticidade do erro padrão. Professores: $n=2.001$. Não Professores: $n=5.006$.

${ }^{* *}$ Significância 5\%. 
Tabela 6. Diferença nos quantis.

\begin{tabular}{lccc}
\hline Quantil & Professor & Não Professor & Teste de diferença \\
\hline $10^{\circ}$ quantil & 4,733 & 3,572 & $* *$ \\
$50^{\circ}$ quantil & 9,499 & 6,925 & $* *$ \\
$90^{\circ}$ quantil & 18,943 & 18,831 & \\
\hline
\end{tabular}

Nota: Teste realizado por regressão simples.

${ }^{* *}$ Diferença significativa com teste bicaudal de valor $95 \%$.

Tabela 7. Decomposição Oaxaca-Blinder para o Salário Horário Médio.

\begin{tabular}{|c|c|c|c|c|c|c|}
\hline \multirow[b]{2}{*}{ Variável } & \multicolumn{2}{|c|}{$10^{\circ}$ quantil } & \multicolumn{2}{|c|}{$50^{\circ}$ quantil } & \multicolumn{2}{|c|}{$90^{\circ}$ quantil } \\
\hline & Coef. & EP & Coef. & EP & Coef. & EP \\
\hline \multicolumn{7}{|l|}{ Diferencial } \\
\hline Não Professores & $3,572^{* *}$ & $(0,066)$ & $6,925^{* *}$ & $(0,104)$ & $18,831^{* *}$ & $(0,343)$ \\
\hline Professores & $4,733^{* *}$ & $(0,185)$ & $9,499^{* *}$ & $(0,103)$ & $18,943^{* *}$ & $(0,747)$ \\
\hline Diferença & $-1,161^{* *}$ & $(0,203)$ & $-2,575^{* *}$ & $(0,142)$ & $-0,112$ & $(0,831)$ \\
\hline \multicolumn{7}{|l|}{ Parte explicada } \\
\hline Homem & $0,024^{* *}$ & $(0,011)$ & 0,058 & $(0,033)$ & $0,058^{* *}$ & $(0,220)$ \\
\hline Idade & $-0,047^{* *}$ & $(0,017)$ & $-0,090$ & $(0,045)$ & $-0,028^{* *}$ & $(0,103)$ \\
\hline Cor branca & 0,001 & $(0,003)$ & 0,003 & $0,010)$ & 0,000 & $(0,015)$ \\
\hline Chefe & $-0,001$ & $(0,003)$ & $-0,001$ & $(0,006)$ & $-0,001$ & $(0,021)$ \\
\hline Funcionário Público & $-0,145^{* *}$ & $(0,026)$ & $-0,248^{* *}$ & $(0,126)$ & 0,062 & $(0,275)$ \\
\hline Educação & 0,030 & $(0,018)$ & 0,048 & $(0,039)$ & $-0,043$ & $(0,252)$ \\
\hline Línguas & 0,000 & $(0,010)$ & $-0,002$ & $(0,018)$ & $-0,016$ & $(0,131)$ \\
\hline Matemática & 0,000 & $(0,001)$ & 0,001 & $(0,005)$ & 0,001 & $(0,023)$ \\
\hline Professor & $-0,004$ & $(0,011)$ & $0,041^{* *}$ & $(0,026)$ & 0,035 & $(0,156)$ \\
\hline 150 mil habitantes & $-0,007$ & $(0,010)$ & $-0,010$ & $(0,016)$ & $-0,006$ & $(0,046)$ \\
\hline Região de São Paulo & $-0,032^{* *}$ & $(0,008)$ & $-0,117^{* *}$ & $(0,056)$ & $-0,098^{* *}$ & $(0,352)$ \\
\hline Região de Campinas & $0,020^{* *}$ & $(0,007)$ & $0,052^{* *}$ & $(0,026)$ & $0,031^{* *}$ & $(0,116)$ \\
\hline Total & $-0,160^{* *}$ & $(0,038)$ & $-0,265^{* *}$ & $(0,150)$ & $-0,004$ & $(0,433)$ \\
\hline \multicolumn{7}{|l|}{ Parte não explicada } \\
\hline Homem & 0,113 & $(0,080)$ & 0,018 & $(0,063)$ & $-0,379$ & $(0,196)$ \\
\hline Idade & $-11,147$ & $(5,825)$ & 4,684 & $(4,040)$ & $-6,177$ & $(16,979)$ \\
\hline Cor branca & $-0,238$ & $(0,308)$ & $-0,042$ & $(0,365)$ & $-1,898$ & $(2,010)$ \\
\hline Chefe & $-0,168$ & $(0,082)$ & $-0,071$ & $(0,091)$ & $-0,288$ & $(0,427)$ \\
\hline Funcionário Público & $-0,072$ & $(0,128)$ & $0,206^{* *}$ & $(0,193)$ & 0,521 & $(0,663)$ \\
\hline Educação & $-0,128$ & $(0,436)$ & $-0,095$ & $(0,231)$ & 1,342 & $(1,606)$ \\
\hline Línguas & $-0,023$ & $(0,146)$ & $-0,001$ & $(0,091)$ & $-0,036$ & $(0,526)$ \\
\hline Matemática & $-0,042$ & $(0,048)$ & $-0,003$ & $(0,038)$ & 0,063 & $(0,231)$ \\
\hline Professor & $-0,206$ & $(0,201)$ & 0,057 & $(0,112)$ & 0,441 & $(0,710)$ \\
\hline 150 mil habitantes & $0,412^{* *}$ & $(0,231)$ & $0,368^{* *}$ & $(0,306)$ & $-0,845$ & $(1,856)$ \\
\hline Região de São Paulo & $-0,212$ & $(0,235)$ & $0,608^{* *}$ & $(0,362)$ & $-0,931$ & $(2,937)$ \\
\hline Região de Campinas & 0,051 & $(0,048)$ & $0,195^{* *}$ & $(0,078)$ & $-0,181$ & $(0,481)$ \\
\hline Constante & 10,660 & $(6,470)$ & $-8,234^{* *}$ & $(4,957)$ & 8,261 & $(23,603)$ \\
\hline Total & $-1,001^{* *}$ & $(0,197)$ & $-2,309^{* *}$ & $(0,215)$ & $-0,108$ & $(0,890)$ \\
\hline
\end{tabular}

Notas: Erro padrão calculado por bootstrap. Professores: $n=2.001$. Não Professores: $n=5.006$.

*Significância 1\%. *** Significância 5\%. 
Na mediana, a diferença é de $\mathrm{R} \$ 2,58$ salários por hora a favor dos professores. Novamente, $89 \%$ do diferencial é explicado pela diferença na estrutura de remuneração. No entanto, a contribuição de cada variável para o diferencial pode ser melhor identificada nesse caso, especialmente na parte não explicada. Nessa, a diferença de remuneração da variável funcionário público entre professores e não professores contribui para diminuir o diferencial em R $\$ 0,21$. Resultados nessa mesma direção ocorrem para as variáveis de região e de cidades com mais de 150 mil habitantes. No caso da parte explicada, de modo geral, os resultados são semelhantes ao do décimo quantil. No quantil 90 a diferença de salários entre as categorias não é significativa. Desse modo não existem grandes diferenças ao se analisar a parte explicada e não explicada de forma agregada. Mesmo os coeficientes estatisticamente significativos não chegam a explicar R $\$ 0,01$ da diferença salarial entre os grupos.

De forma geral, observando as tabelas 5 e 6 , é possivel inferir que a diferença salarial se deve, em larga medida, a diferença na estrutura de remuneração entre as categorias sendo esta importância semelhante tanto no quantil 10 como na mediana. Por sua vez, para o quantil 90, o diferencial salarial não se mostrou significativo.

\section{CONCLUSÃO}

Estudar a estrutura de remuneração dos professores de um país é importante por várias razões. Talvez uma das principais delas seja porque a remuneracão pode afetar o esforço que o professor exerce em sala de aula. Além disso, também pode afetar a decisão dos indivíduos de ingressarem na carreira docente. Por fim, pode contribuir para o nível de rotatividade desses profissionais. Nesse sentido, o presente trabalho buscou comparar a diferença salarial entre professores e não professores graduados em carreiras tipicamente relacionadas à profissão docente. 0 objetivo era entender como esses profissionais recém graduados escolheram diferentes ocupações (docente versus não docente) levando ao aparecimento de um diferencial salarial importante já nos primeiros anos de vida profissional. O fato de que esse diferencial se mostrou heterogêneo de acordo com os diferentes quantis nos levou a aplicar a decomposição de Firpo et al. (2009) nos quantis 10, 50 e 90.

$\mathrm{Na}$ análise do diferencial nos quantis de salário é possivel inferir que o diferencial é majoritariamente devido a parte não explicada da decomposição, ou seja, é a diferença na estrutura de remuneração das categorias a favor dos professores que explica cerca de $85 \%$ do diferencial. Essa proporção é semelhante tanto para os profissionais de menor rendimento (quantil 10) como para os da mediana. Cabe aqui destacar que o resultado da decomposição tradicional de Oaxaca-Blinder para a média também indicou uma contribuição em torno de $85 \%$ da parte não explicada. Para os indivíduos do quantil 90 o diferencial de salário não se mostrou significativo. Desse modo, nossos resultados corroboram os já existentes na literatura para o Brasil (Becker, 2008) e Chile (Mizala \& Romaguera, 2004).

$O$ fato de encontrarmos um diferencial salarial favorável aos professores na média e nos quantis 10 e 50 da distribuição salarial mostra que a carreira docente parece ser uma escolha atrativa para os formados nas licenciaturas aqui investigadas. Por um lado, não parece que as eventuais diferenças de composição no grupo de professores e não-professores explique parte relevante desse hiato salarial. Por outro lado, o maior retorno para os professores de características ligadas aos mercados de trabalho locais (como porte de município e região do estado de São Paulo em que o indivíduo reside) parecem ser os principais aspectos associados a melhor remuneração dos professores. Um fator não considerado explicitamente nesse trabalho e que pode explicar o hiato salarial favorável aos docentes seria a distribuição dos profissionais de maior "habilidade" (não observável ao pesquisador). É possível que dentre os graduados nessas licenciaturas, os mais habilidosos escolheram a ocupação docente, fazendo com que ganhem mais que os demais profissionais praticamente em toda a distribuição salarial. Isso só não ocorre para os percentis elevados, nos quais o diferencial salarial em prol dos docentes desaparece. Nesse caso, ocupações não docentes conseguiriam atrair os profissionais mais habilidosos.

No entanto, um ponto de atenção nessa explicação é que se considerarmos todos os graduados em nível superior, é possível que os formados nas licenciaturas aqui investigadas não sejam os mais habili- 
dosos. Assim, estaríamos aqui investigando o gap salarial entre indivíduos de baixa "habilidade". Nesse sentido, duas políticas poderiam melhorar o perfil dos docentes bem como a atratividade dessa carreira: i) capacitar os profissionais dessas licenciaturas (tanto durante como após o ensino superior) de forma a aumentar a produtividade e habilidade dos mesmos; ii) relaxar os requisitos de entrada na profissão docente, permitindo a entrada de graduados em outras áreas não tipicamente docentes como estímulo para atrair mais graduados habiliosos para a docência.

\section{REFERÊNCIAS BIBLIOGRÁFICAS}

Bacolod, M. P. (2006, July). Do alternative opportunities matter? The role of female labor markets in the decline of teacher quality (CES N ${ }^{0}$ 06-22). Washington DC: Center for Economic Studies, Bureau of the Census.

Barber, M., \& Moushed, M. (2007). How the world's best performing education systems comes out on top. (The McKinsey Report). McKinsey \& Company.

Becker, K. L. (2008). A remuneração do trabalho do professor no ensino fundamental público brasileiro (Dissertação, Universidade de São Paulo, Escola Superior de Agricultura "Luiz de Queiroz", Piracicaba SP). Disponível em: http://www.teses.usp.br/teses/disponiveis/11/11132/tde-12022009-091749/pt-br.php

Bishop, J. H. (1989). Is the test score decline responsible for the productivity growth decline? American Economic Review, 79(1), 178-197. Disponível em: http://www.jstor.org/stable/1804780

Brewer, D. J. (1996). Career paths and quit decisions: Evidence from teaching. Journal of Labor Economics, 14(2), 313-339. Disponível em: http://www.jstor.org/stable/2535355

Britto, A. M., \& Waltenberg, F. D. (2014). É atrativo tornar-se professor do ensino médio no Brasil? Evidências com base em decomposições paramétricas e não-paramétricas. Estudos Econômicos, 44(1), 5-44. doi: 10.1590/S0101-41612014000100001

Chevalier, A., Dolton, P. \& McIntosh, S. (2007). Recruiting and retaining teachers in the UK: An analysis of graduate occupation choice from the 1960s to the 1990s. Economica, 74(293), 69-96. doi: 10.1111/j.14680335.2006.00528.x

Firpo, S., Fortin, N. M. \& Lemieux, T. (2009). Unconditional quantile regressions. Econometrica, 77(3), 953-973. doi: 10.3982/ECTA6822

Gilpin, G. A. (2011, August). Reevaluating the effect of non-teaching wages on teacher attrition. Economics of Education Review, 30(4), 598-616. doi: 10.1016/j.econedurev.2011.03.003

Hanushek, E. A. (1986). The economics of schooling: Production and efficiency in public schools. Journal of Economic Literature, 24(3), 1141-1177. Disponivel em: http://hanushek.stanford.edu/sites/default/files/ publications/Hanushek\%201986\%20JEL\%2024(3).pdf

Imazeki, J. (2005, August). Teacher salaries and teacher attrition. Economics of Education Review, 24(4), 431-449. doi: 10.1016/j.econedurev.2004.07.014

Juhn, C., Murphy, K. M. \& Pierce, B. (1993). Wage inequality and the rise in returns to skill. Journal of Political Economy, 101(3), 410-442. Disponível em: http://www.jstor.org/stable/2138770

Kimko, D. D., \& Hanushek, E. A. (2000). Schooling, labor-force quality, and the growth of nations. American Economic Review, 90(5), 1184-1208. doi: 10.1257/aer.90.5.1184

Lakdawalla, D. (2006). The economics of teacher quality. The Journal of Law \& Economics, 49(1), 285-329. doi: $10.1086 / 501083$

Menezes-Filho, N. A. (2001, Março). A evolução da educação no brasil e seu impacto no mercado de trabalho (paper). Instituto Futuro Brasil.

Menezes-Filho, N. A., \& Pazello, E. (2007). Do teachers' wages matter for proficiency? Evidence from a funding reform in Brazil. Economics of Education Review, 26(6), 660-672. doi: 10.1016/j.econedurev.2007.08.003 
Mizala, A., \& Romaguera, P. (2004, July). Teachers' salary structure and incentives in Chile (Documentos de Trabajo $\mathrm{N}^{0}$ 193). Centro de Economía Aplicada - Universidad de Chile.

Moriconi, G. M., \& Marconi, N. (2008, dezembro). Os salários dos professores públicos são atrativos no Brasil? In XXXVI Encontro Nacional de Economia, Salvador BA. Disponível em: http://www.anpec.org.br/ encontro2008/artigos/200807211605210-.pdf

Oaxaca, R. (1973). Male-female wage differentials in urban labor markets. International Economic Review, 14(3), 693-709. Disponível em: http://www.jstor.org/stable/2525981

OECD. (2012). PISA 2012 results: Excellence through equity: Giving every student the chance to succeed (Vol. II). OECD Publishing. doi: 10.1787/9789264201132-en

Stoddard, C. (2003). Why has the number of teachers per student risen while teacher quality has declined? The role of changes in the labor market for women. Journal of Urban Economics, 53(3), 458-481. doi: 10.1016/S00941190(03)00004-4 